\title{
Pemberdayaan dan Strategi Marketing Petani Madu Desa Giri Tengah Kecamatan Borobudur-Magelang
}

\author{
Andreani Hanjani ${ }^{1}$, Puspita Dewi Wulaningrum ${ }^{2}$ \\ Universitas Muhammadiyah Yogyakarta \\ 1e-mail:andreani@umy.ac.id; Hp.085641376057 \\ ²email:puspitadewi@umy.ac.id; Hp.081804313217
}

\begin{abstract}
ABSTRAK
Tujuan Program Pengabdian ini adalah untuk meningkatkan pemberdayaan kelompok petani madu ekonomi produktif desa Giri Tengah Kecamatan Borobudur membentuk individu dan masyarakat menjadi mandiri. Mitra Usaha dalam program ini adalah petani lebah bernama Bp. Wijarso dan Bp. Bambang. Permasalahan yang dihadapi oleh kedua mitra tersebut adalah produk UKM madu kaliandra desa Giri Tengah belum memiliki branding produk dan label kemasan sehingga pemasaran produk UKM madu kaliandra tidak maksimal. Selain itu, mitra masih kurang mengetahui membuat laporan hasil usaha. Metode pelaksanaan pengabdian ini yaitu: 1)Survey dengan melakukan pengamatan dan analisis; 2)Branding produk madu;3) Strategi Marketing agar produk lebih menarik dan dikenal; 4)Pelatihan pembuatan laporan keuangan sederhana hasil usaha. Hasil program ini adalah: 1) Produk madu memiliki label nama produk yang menarik dan lebih dikenal konsumen; 2)Pelatihan pembuatan laporan keuangan sederhana hasil usaha. Program ini diharapkan mampu memfasilitasi mitra untuk mempermudah melakukan penyajian laporan keuangan.
\end{abstract}

Kata Kunci: Pemberdayaan, Pelatihan, Strategi Marketing, Branding

\begin{abstract}
The purpose of the Community Service Program is to increase the empowerment of farmers in the productive economy, the village of Giri Tengah, Borobudur Subdistrict, forming individuals and communities to become independent. Business Partners in this program are bee farmers named Bp. Wijarso and Mr. Bambang. The problems faced by these two partners are UKM products kaliandra honey, Giri Tengah village, which do not have product branding and packaging labels, so the marketing of UKM products Kaliandra honey is not optimal. In addition, partners are still not aware of making reports on business results. The method of implementing this service is: 1) Survey by conducting observations and analysis; 2) Honey product branding; 3 ) Marketing strategy so that products are more attractive and known; 4) Training on making simple financial statements of business results. The results of this program are: 1) Honey products have an attractive and better known product name label; 2) Training on making simple financial statements of business results. This program is expected to be able to facilitate partners to facilitate the presentation of financial statements.
\end{abstract}

Keywords: Empowerment, Training, Marketing Strategy, Branding 


\section{PENDAHULUAN}

Salah satu daerah yang memiliki potensi besar kekayaan alam dan usaha ekonomi seperti UKM adalah desa Giri Tengah. Desa Giri Tengah terletak di ujung selatan Kecamatan Borobudur, berjarak sekitar $5 \mathrm{~km}$ ke arah barat daya dari Candi Borobudur. Sebagian besar wilayah Desa Giri Tengah terletak di lereng atau kaki Bukit Menoreh. Desa Giri Tengah terdiri dari 6 dusun yaitu Kalitengah, Mijil, Ngaglik, Kamal, Gedangsambu, dan Onggosoro. Mayoritas penduduk Desa Giri Tengah bermata pencaharian sebagai petani.

Desa Giri Tengah telah berkembang usaha budidaya lebah madu. Hal ini sangat didukung oleh kondisi lingkungan yang potensial, karena di sekitar perbukitan Menoreh banyak sekali jenis pakanan lebah seperti bunga pohon Kaliandra, didukung oleh tanaman bunga jagung dan pohon pendamping seperti pohon randu. Peternak lebah tersebar di beberapa dusun. Kini paguyuban peternak lebah sudah didirikan untuk mewadahi kebutuhan para peternak lebah dan membuat jadi madu. Sudah ada koperasi yang berdiri dan memiliki 1.200 sangkat. Kami bekerjasama dengan dua mitra, yang pertama adalah petani lebah bernama Bp.Wijarso dan mitra yang kedua bernama Bp.Bambang.

Hasil UKM madu kaliandra desa Giri Tengah kurang didengar dipasaran. Hal ini disebabkan karena belum adanya branding produk dan pemasaran produk tersebut. Kekurangpahaman masyarakat mengenai branding produk dan cara pemasaran produk ini membuat hasil potensi masyarakat desa Giri Tengah kurang laku dipasaran. Selain itu, masyarakat desa Giri Tengah juga kurang paham mengenai pembukuan hasil kegiatan usahanya sehingga mereka sering mencampurkan pendapatan hasil usaha dengan uang kebutuhan harian mereka.

Adapun Rumusan masalah adalah sebagai berikut: 1) Bagaimana branding produk agar menarik; 2) Bagaimana model pelatihan laporan keuangan sederhana hasil usaha.

Berdasarkan masalah diatas maka dilaksanakan program pelatihan dan pemberdayaan pembuatan branding produk dan laporan keuangan sederhana hasil usaha. Luaran dari pengabdian ini adalah publikasi jurnal Berdikari. 


\section{BAHAN DAN METODE}

Metode

Jenis Data

Tehnik

Target Hasil

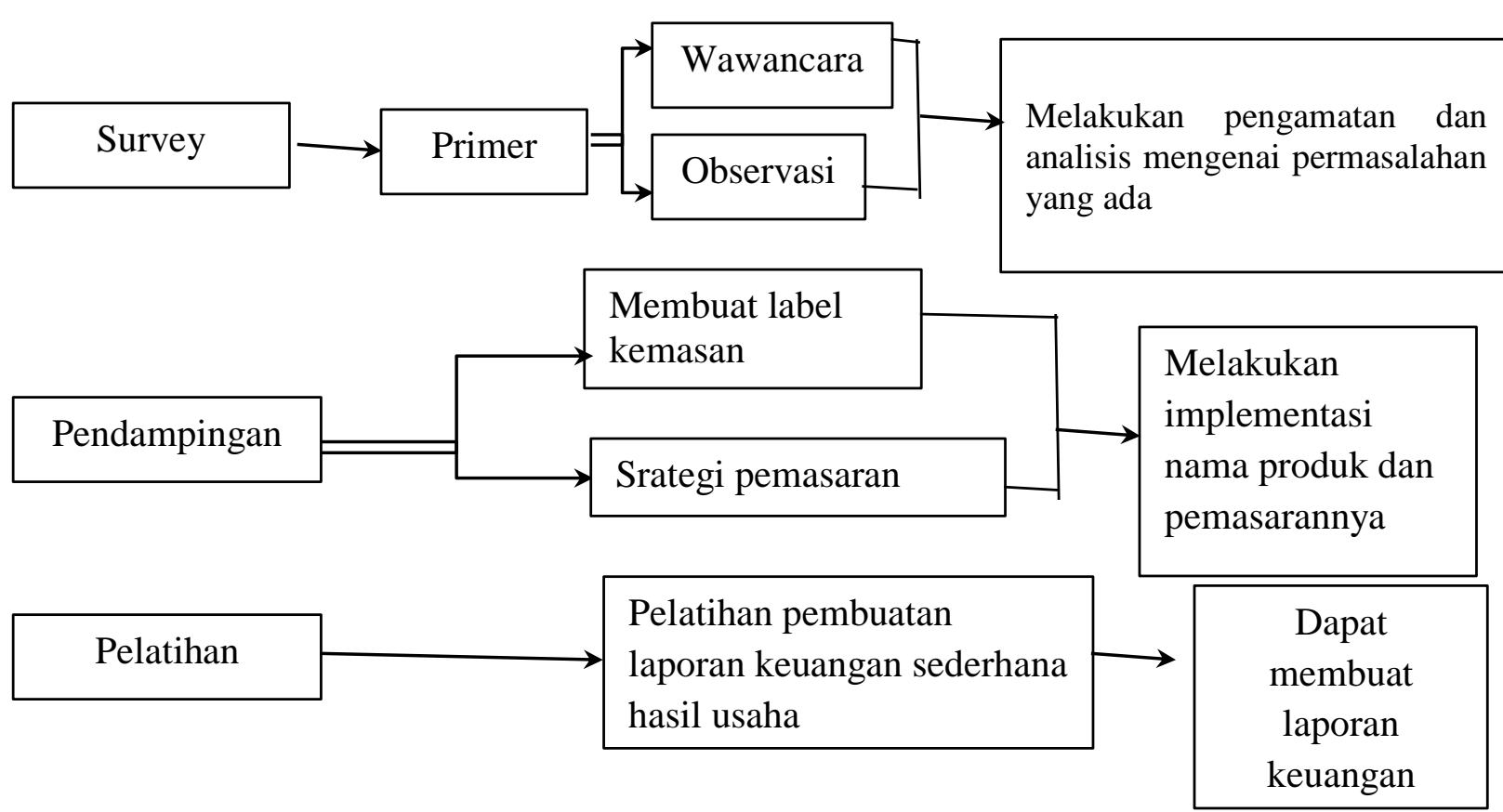

Gambar 1.

Metode Pelaksanaan Program

\section{HASIL DAN PEMBAHASAN}

\section{Pemberdayaan Kepada Petani Madu Desa Giri Tengah}

Dalam rangka pemberdayaan petani madu desa giri tengah tim pelaksana membantu membuatkan branding madu dan melakukan pelatihan laporan kegiatan usaha.

A. Branding madu

Tim pelaksana membantu petani madu giri tengah untuk membuat branding produk madunya. Nama Kemasan Madu Asli Giri Tengah adalah "Giri Bee Asli Giri Tengah Borobudur". Madu memiliki khasiatnya masing-masing sehingga ada yang madu insulin dari pohon insulin untuk penderita diabetes, madu bunga kaliandra untuk yang berasal dari bunga kaliandra. 

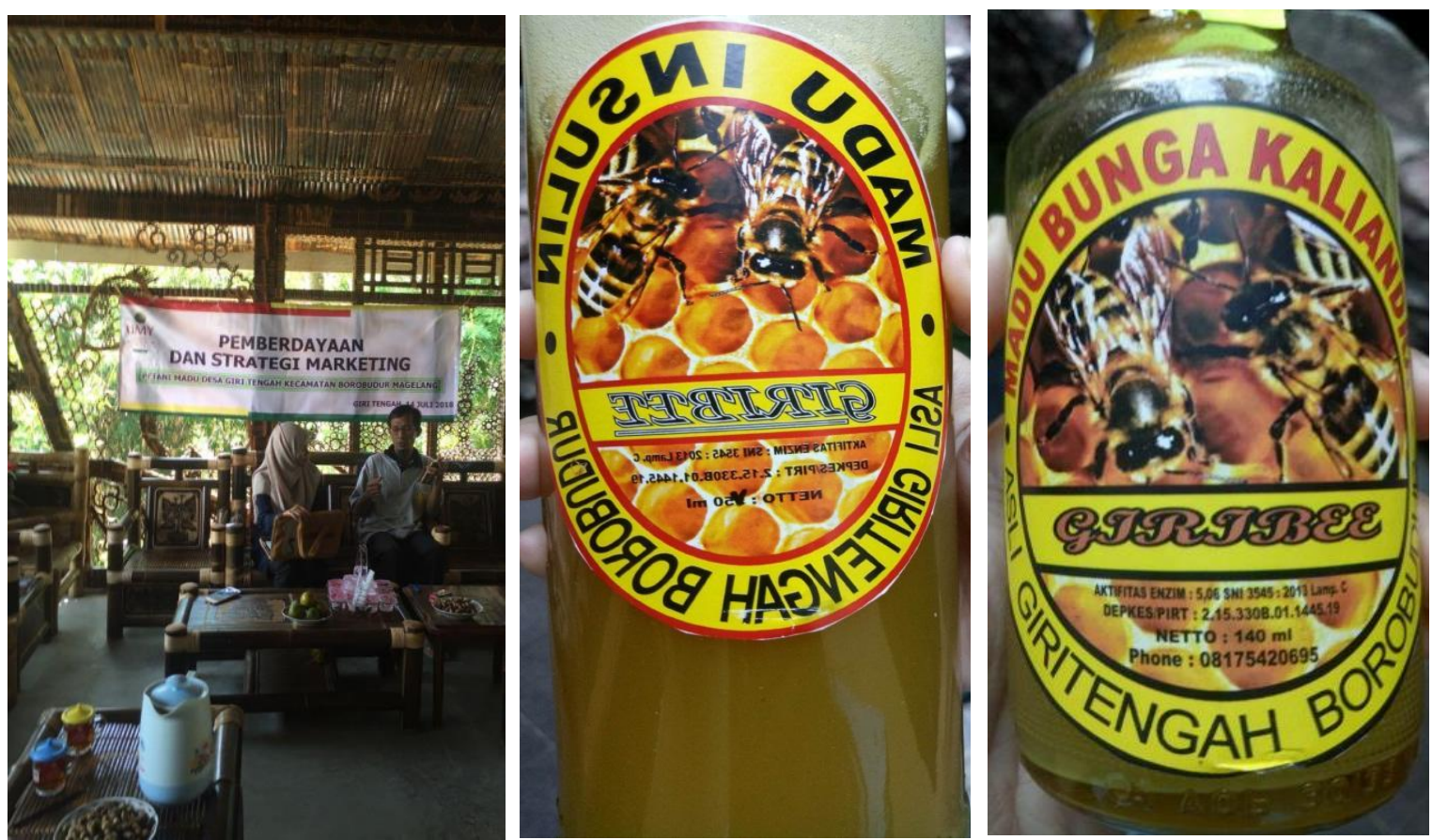

Gambar 2.

Branding nama madu

B. Pelatihan laporan kegiatan usaha

Awal mula petani madu desa giri tengah belum memiliki laporan kegiatan usaha. Oleh karena itu tim pelaksana melakukan pelatihan laporan kegiatan usaha agar dapat mengetahui keluar masuk pendapatan yang diperoleh, menghitung harga pokok produksi, dan laporan laba rugi. Kegiatan yang kami lakukan sebagai berikut:
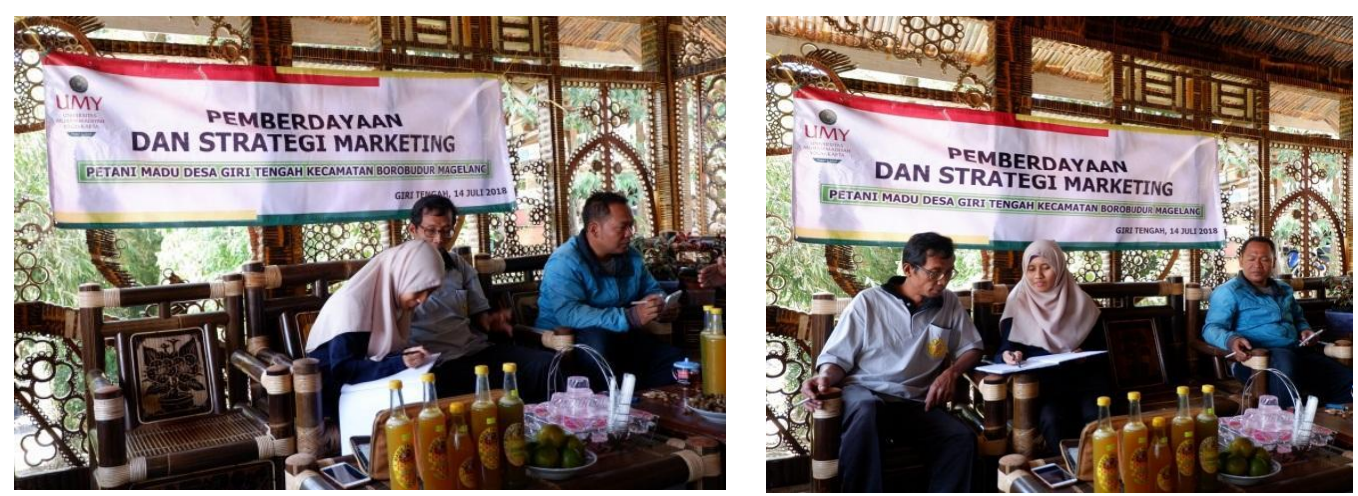

Gambar 3.

Pelatihan Laporan Kegiatan Usaha 
Berikut ini bentuk tabel pendapatan yang kami ajarkan:

Tabel 1.

Pendapatan

\begin{tabular}{|l|l|l|l|l|l|l|l|l|}
\hline \multirow{2}{*}{ No } & \multirow{2}{*}{$\begin{array}{l}\text { Nama } \\
\text { Barang }\end{array}$} & \multicolumn{3}{|c|}{ Masuk } & \multicolumn{3}{c|}{ Keluar } & \multirow{2}{*}{ Keuntungan } \\
\cline { 3 - 8 } & & Kuantitas & Beli & Jumlah & Kuantitas & $\begin{array}{l}\text { Harga } \\
\text { Jual }\end{array}$ & Jumlah & Kotor \\
\hline & & & & & & & & \\
\hline & & & & & & & & \\
\hline & & & & & & & & \\
\hline
\end{tabular}

\section{Pendampingan Strategi Marketing kepada Petani Madu Desa Giri Tengah}

Dalam rangka marketing untuk promosi madu " Giri Bee Asli Giri Tengah Borobudur" kami mengajarkan melalui media sosial kekinian yaitu instagram. Kami mengajarkan untuk memposting produk dengan memberikan "\#” untuk mengundang dari komunitas instagram dari berbagai kalangan agar mengetahui produk tanpa harus berteman dengan instagram madu giri tengah untuk memperluas jaringan. Selain itu kami juga membuat video untuk memposting kegiatan paket wisata panen lebah madu untuk mengetahui proses pemanenan madu. Tim pelaksana juga memberikan tempat display produk untuk memajang produk madu agar lebih menarik. Berikut kegiatan yang kami lakukan: 

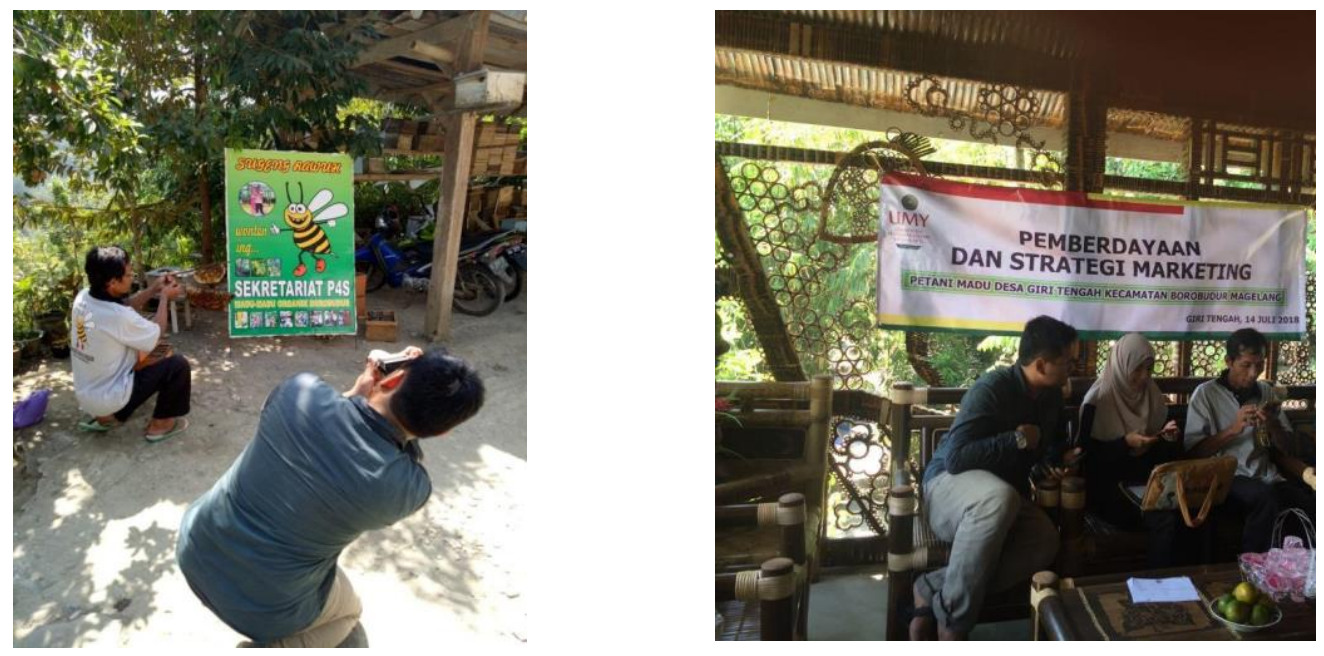

Gambar 4.

Strategi Marketing
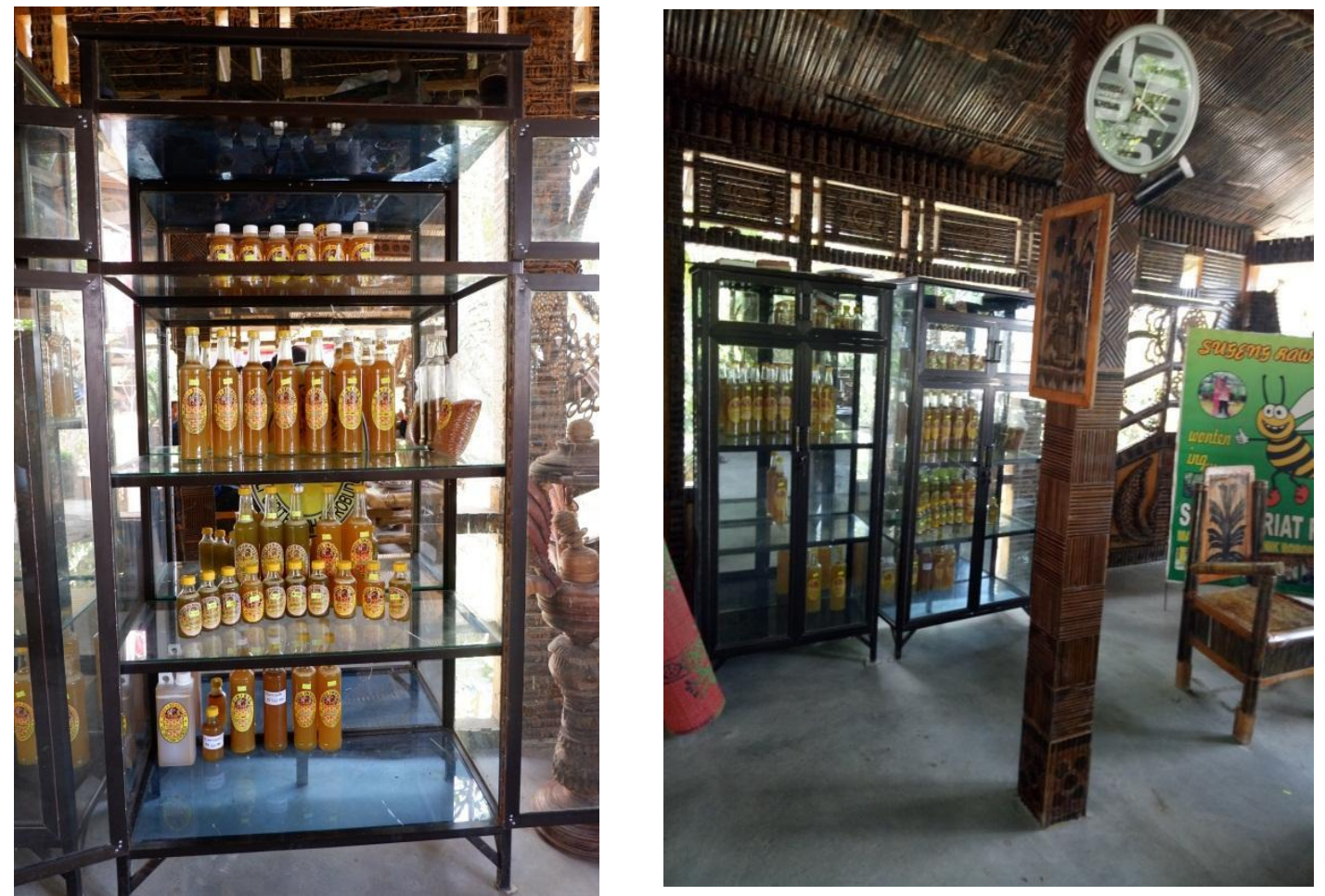

Gambar 5.

Tempat display produk 


\section{SIMPULAN}

Tujuan pelaksanaan adalah untuk meningkatkan pemberdayaan kelompok petani madu ekonomi produktif desa Giri Tengah Kecamatan Borobudur membentuk individu dan masyarakat menjadi mandiri. Dari hasil pelaksanaan kegiatan seperti pemasaran dan pelatihan pelaporan keuangan sederhana didapatkan pengetahuan kepada petani madu untuk dapat memasarkan produknya agar lebih menarik dan dikenal konsumen.

Dari semua program diajukan saran-saran yakni untuk kedepannya demi optimalnya produk madu di desa Giri Tengah diperlukan teknologi tepat guna yang lebih modern untuk pemeras madu sehingga dihasilkan madu dengan kualitas terjaga bersih tanpa kotoran dibandingkan diperas secara manual.

\section{UCAPAN TERIMA KASIH}

Kami mengucapkan terima kasih kepada:

1. Pemerintah Desa Giri Tengah

2. Petani Madu Desa Giri Tengah

\section{DAFTAR PUSTAKA}

Bruhn, M. 2003. Relationship Marketing. New Jersey: Prentice Hall

Darmawan, A. 2003. Segmentation, Targeting, dan Positioning Produk Madu PT.Madu

Pramuka.

Koontz ,Harold, dkk (1984), Manajemen, Erlangga, Jakarta

Kotler, P. dan K. L. Keller. 2007. Manajemen Pemasaran I. Jakarta: PT. Indeks.

Sarwono, B. 2005. Lebah Madu. Agro MediaPustaka. Jakarta

Sulistyani.Ambar Teguh.2004.Kemitraan Dan Model-model Pemberdayaan.Gava Media:Yogyakarta.

Sunyoto, Danang (2012), Dasar-Dasar Manajemen Pemasaran, Cetakan ke 1, Penerbit Caps Yogyakarta

Tjiptono, F. 1997. Strategi Pemasaran. Penerbit Andi. Yogyakarta.

Widjaja, HAW.2003.Otonomi Desa Merupakan Otonomi Asli Bulat dan Utuh. Jakarta: PT. Raja Grafindo Persada. 